\title{
Effects of Adding Boron Compounds to Glycol Based Grinding Aids on Cement Compressive Strengths Performance
}

\author{
Murat Çallı1,2*, Erol Pehlivan'1 \\ ${ }^{1}$ Department of Chemical Engineering, Selcuk University, Konya, Turkey \\ ${ }^{2} \mathrm{R} \&$ D Department, SYCS Insaat ve Cimento A.S., Baskil, Turkey \\ Email: *muratcalli42@gmail.com, erolpehlivan@gmail.com
}

How to cite this paper: Çalli, M. and Pehlivan, E. (2019) Effects of Adding Boron Compounds to Glycol Based Grinding Aids on Cement Compressive Strengths Performance. Open Journal of Civil Engineering, 9, 35-45.

https://doi.org/10.4236/ojce.2019.91003

Received: December 21, 2018

Accepted: March 8, 2019

Published: March 11, 2019

Copyright $\odot 2019$ by author(s) and Scientific Research Publishing Inc. This work is licensed under the Creative Commons Attribution-NonCommercial International License (CC BY-NC 4.0). http://creativecommons.org/licenses/by-nc/4.0/

\begin{abstract}
In this study, the effect of substituting boron compounds with glycol-based grinding aids to the compressive strength performances of cement was investigated. Monoethylene glycol (MEG) and diethylene glycol (DEG) were used as glycol-based grinding aids, and anhydrous borax and boric acid were used as boron compounds in the tests. CEM I type cement production was carried out with the addition of grinding aid mixtures to Portland clinker and some gypsum in the experiments. All produced cement samples were tested for Blaine fineness, xrf elemental analysis and 2, 7 and 28 days compressive strength tests. Test results of grinding aids of MEG and boron compounds mixture showed no increase in any age of compressive strengths performances related to MEG used itself. However, with the addition of boron compounds to DEG increased grinding aid performance at all ages $(2,7$ and 28 days). Possible reasons for this increase could be borate esters formed with DEG and boric acid in a basic medium.
\end{abstract}

\section{Keywords}

Boric Acid, Cement, Glycol, Grinding Aid, Anhydrous Borax, Compressive Strength

\section{Introduction}

Many chemicals have been used as a grinding aid in scientific studies and in the industry. Amines such as triethylenetetramine, aminalols such as diethanolamine, glycol compounds such as ethylene glycol, phenol, and phenol derivatives, and also many more complex compounds were used as grinding aid [1]. Katsioti 
and colleagues [2] evaluated six commercial grinding additives used in the production of Portland cement. In this study, in all cases, the addition of grinding aid resulted with the development of the specific surface and the grindability index. Results were caused to the ability to reduce the resistance to friability and the aid ability to prevent agglomeration to balls and mill inside. Sohoni and others investigated the efficiency of the Portland cement clinker, limestone and quartz in their batch production in a laboratory-type ball mill with seven grinding aids which were triethanolamine, mono- and diethylene glycols, oleic acid, sodium oleate, sulfite waste liquor and dodecylbenzene sulfonic acid. It was determined that all used grinding aids influence at different grades. Grinding aids had adverse effect only on quartz grinding, but have significant beneficial effects on grinding limestone and clinker [3]. Jeknavorian and others had identified phenol, 5-glycol, and alkanolamine compounds in cement with the test technique they found [4]. Grinding process depends on the control of the agglomeration force of the product. It has been shown that particle size and grinding energy consumption can be reduced by using grinding aids [5] [6].

There were studies on boron and cement. Much of these studies were about using boron compounds as mineral additive materials in portland cement. In the work of Elbeyli and his colleagues, the effects of ordinary borogypsum and calcined borogypsum on portland cement were studied. The cement prepared with borogypsum (5\%) did not change in its strength for 28 days compared to that prepared with natural gypsum but reported that the $(5 \%)$ hemihydrate borogypsum mixed cement provided 25\% strength increase [7]. Erdogan and others used borogypsum which was a by-product of boric acid plants. It mainly consisted of $\mathrm{CaSO}_{4} \cdot 2 \mathrm{H}_{2} \mathrm{O}$ and secondly $\mathrm{B}_{2} \mathrm{O}_{3}$ and some other impurities. Borogypsum was refined more to reduce $\mathrm{B}_{2} \mathrm{O}_{3}$ ratio, and this new blend was used in the tests. Results showed that this refined borogypsum could be used for ordinary portland and puzzolana cement [8]. In another study, $1 \%$ and $1.5 \%$ boron containing clay waste added cement samples showed better strength than the reference cement. Two different boron containing clays were used in the experiments. The $\mathrm{B}_{2} \mathrm{O}_{3}$ content was $19.78 \%$ and $9.63 \%$ respectively [9]. Study on the effects on cement properties by using borax pentahydrate mineral in Portland cement mix had shown that the borax mineral could be used up to $10 \%$ [10]. However, as borax content increased, the strength of cement that was containing borax decreased. The cement mix prepared using $1 \%$ to $5 \%$ colemanite which had $\mathrm{B}_{2} \mathrm{O}_{3}$ content of $17.65 \%$ showed a slight increase in 28 days compressive strength compared to the reference cement. Also, the compressive strength results of colemanite admixtures were better when prepared by mixing with fly ash and coal boiler bottom ash [11]. The reaction between the boron compounds and $\mathrm{Ca}(\mathrm{OH})_{2}$ which occurred during hydration helps the bond formed between the particles, and this increases the compressive strength [12].

In another study, two different grinding aids industrial amine-based (TEA + TIPA) and glycol-based (MEG + DEG) were used [13]. In all tests, the cement 
fineness was kept constant $\left(3500 \mathrm{~cm}^{2} / \mathrm{gr}\right.$ Blaine value). The rheological properties and strength results of the test cement were examined. There was a decrease of more than $2 \mathrm{MPa}$ (approx. 4.7\%) in the 28-day strength of the glycol-based $0.1 \%$ dosing grinding aids compared to the reference cement produced. In another study, the effect of grinding aids on the amount of clinker usage and the amount of grinding energy consumed during grinding was investigated [14]. Amines, glycols, and acids were used in this study as grinding aids. The glycolic grinding aid used was a mixture of diethylene glycol (DEG) and propylene glycol (PG). In experiments which glycol-based grinding aids added up to $0.08 \%$ doses, a compressive strength increase of up to $8 \%$ was determined at 28 days compressive strength relative to reference cement. However, at higher doses (e.g., $0.11 \%$ ) there was an increase in water requirement, a decrease in Blaine value and a decrease in 28 days strength.

Schrabback showed positive effect of addition of polycarboxylate ether to common grinding aid. In the study the performance which previously achieved with glycol-based grinding aid as $9 \%$ increase in production was easily achieved as $16 \%$ production increase with the glycol-based grinding aid formulated with PCE [15]. PCE reacted like low molecular weight compounds in cement grinding and subsequent hydration reactions. Duan-le and others investigated the effects of organic compounds containing ester groups on cement hydration and hardening [16]. Five different ester group organic compounds (ethyl acetate, dimethyl oxalate, glyceryl triacetate, trimethyl phosphate and triethanolamine borate) were used. Esters had been found to delay the early stages of hydration. In all other organic compounds except trimethyl phosphate, the 3 days and 28 days compressive strength increased. As well, the study concluded that the increase in the number of ester groups increased the effectiveness of cement hydration and the effect of the presence of functional groups such as phosphate or borate affected the role of the esters.

Instead of conventional grinding aids, the use of these chemicals in combination with different polymers or chemicals can demonstrate more efficient grinding aid performance. For glycol-based grinding aids and boron compounds, there is no available study for this purpose.

\section{Materials and Methods}

\subsection{Materials and Equipment}

Portland cement clinker and some gypsum were used as the main components of the cement. The elemental analyzes of the used clinker and gypsum are in Table 1. Monoethyleneglycol and diethylene glycol were used as a glycol-based

Table 1. XRF elemental analysis of clinker and gypsum used in the experiments.

\begin{tabular}{ccccccccc}
\hline Material & $\mathrm{SiO}_{2} \%$ & $\mathrm{Al}_{2} \mathrm{O}_{3} \%$ & $\mathrm{Fe}_{2} \mathrm{O}_{3} \%$ & $\mathrm{CaO} \%$ & $\mathrm{MgO} \%$ & $\mathrm{SO}_{3} \%$ & $\mathrm{~K}_{2} \mathrm{O} \%$ & $\mathrm{Na}_{2} \mathrm{O} \%$ \\
\hline Clinker & 21.11 & 4.88 & 3.97 & 64.24 & 1.15 & 1.61 & 0.88 & 0.23 \\
Gypsum & 0.79 & 0.16 & 0.19 & 31.45 & 0.11 & 44.22 & 0.02 & 0.06 \\
\hline
\end{tabular}


grinding aids. Boric acid and anhydrous borax (Eti Maden) were used as the boron compounds whose effects on the performance of grinding aids were investigated. Precision scales, laboratory type crusher, laboratory type mill, mortar mixer, shaking table, compressive strength testing machine, mortar molds [40 $\mathrm{mm} \times 40 \mathrm{~mm} \times 160 \mathrm{~mm}$ ], humidity conditioning cabinet, curing pool, CEN standard sand, pure water, XRF, Blaine fineness equipment, steel buckets, beakers and pipettes were used in the experiments.

\subsection{Experimental Methods}

The size of the clinker was reduced ( $3 \mathrm{~mm}$ or less) by passing it through the laboratory type crusher before the experiments to ensure homogeneity and then mixed. In the tests, Portland CEM I type cement conforming to TS EN 197-1: 2012 standard was produced [17]. Grinding aids except the reference cement were used in all the cement produced in the experiments. For each experiment, $3000 \mathrm{~g}$ of clinker was weighed, and then the grinding aid + boron compound was added to give a total weight of $0.1 \%$ cement, and mixed well. The laboratory type ball mill was loaded with clinker and grinding aid mixture and operated for 40 minutes. Samples were taken from the stopped mill, and the $\mathrm{SO}_{3}$ level was checked. Gypsum was added into the mill according to the final target $\mathrm{SO}_{3}$ level $[3.05 \% \pm 0.05]$, and the mill was operated for another 40 minutes. At the end of 80 minutes milling, cement samples were taken separately for XRF elemental analysis and Blaine fineness test (Table 2). Mortar specimens were prepared for strength tests according to TS EN 196-1 standard, and 2, 7 and 28-day strength tests were performed (Table 2) [18].

Each experiment mixture was prepared 3 times according to experimental design, was ground seperately then all of these three seperate samples of the same experimental design mixture were mixed. One average representative sample was taken from this mixture of three seperate ground cement for the tests. One reference cement composed of clinker and gypsum was produced without any grinding aid addition. As a grinding aid mixture 100\% monoethyleneglycol (3 g), $75 \%$ monoethyleneglycol $(2.25 \mathrm{~g})$ and $25 \%$ boric acid $(0.75 \mathrm{~g}), 67 \%$ monoethyleneglycol $(2 \mathrm{~g})$ and $33 \%$ boric acid $(1 \mathrm{~g})$ were used. All test recipes were repeated with the same ratios by using anhydrous borax instead of boric acid. Tests were repeated for diethylene glycol as glycol based grinding aid, and all other mixture components and ratios were the same.

\section{Results and Discussion}

All experiments using MEG and MEG + BA as grinding aid (100\% MEG, 75\% $\mathrm{MEG}+25 \% \mathrm{BA}, 67 \% \mathrm{MEG}+33 \% \mathrm{BA}$ ) yielded higher compressive strength results than reference cement sample (Figure 1) at all ages of mortar strengths (2,7 and 28 days). In experiments using 100\% MEG, all results gave the highest results in 2, 7 and even 28 days compressive strength ages. BA used with MEG as a grinding aid failed to show substitution for MEG, and the addition of $25 \%$ and 
Table 2. Reference cement and ground with grinding aids + boron compounds experiment cements Blaine fineness, water demand, density, 2, 7 and 28 days compressive strength results and XRF elemental analysis of ground cement with the boron compound.

\begin{tabular}{|c|c|c|c|c|c|c|c|c|c|c|c|}
\hline $\begin{array}{l}\text { Grinding Aid } \\
\text { Mixture }\end{array}$ & $\begin{array}{c}\text { (Reference } \\
\text { Cement) \%0 } \\
\text { Grinding Aid }\end{array}$ & $\begin{array}{l}\% 100 \\
\text { MEG }\end{array}$ & $\begin{array}{c}\% 100 \\
\text { DEG }\end{array}$ & $\begin{array}{c}\% 75 \\
\text { MEG+ } \\
\% 25 \mathrm{BA}\end{array}$ & $\begin{array}{c}\% 75 \\
\text { DEG+ } \\
\% 25 \mathrm{BA}\end{array}$ & $\begin{array}{c}\% 75 \\
\text { MEG+ } \\
\% 25 \text { AHB }\end{array}$ & $\begin{array}{c}\text { \%75 } \\
\text { DEG+ } \\
\% 25 \text { AHB }\end{array}$ & $\begin{array}{c}\% 67 \\
\text { MEG+ } \\
\% 33 \mathrm{BA}\end{array}$ & $\begin{array}{c}\% 67 \\
\text { DEG+ } \\
\% 33 \mathrm{BA}\end{array}$ & $\begin{array}{c}\text { \%67 } \\
\text { MEG+ } \\
\% 33 \text { AHB }\end{array}$ & $\begin{array}{c}\% 67 \\
\text { DEG+ } \\
\% 33 \mathrm{AHB}\end{array}$ \\
\hline $\begin{array}{c}2 \text {-Day } \\
\text { Compressive } \\
\text { Strength }(\mathrm{MPa})\end{array}$ & 27 & 32.5 & 29.5 & 30.6 & 29.6 & 31.8 & 31.3 & 31.3 & 30.6 & 31.7 & 30.6 \\
\hline $\begin{array}{c}7 \text {-Day } \\
\text { Compressive } \\
\text { Strength }(\mathrm{MPa})\end{array}$ & 37.7 & 44 & 38.2 & 39.7 & 38.4 & 41.4 & 39.8 & 41 & 39.3 & 41.4 & 40.4 \\
\hline $\begin{array}{c}28 \text {-Day } \\
\text { Compressive } \\
\text { Strength }(\mathrm{MPa})\end{array}$ & 48.1 & 52.6 & 45.4 & 49.7 & 47.7 & 51.2 & 48.8 & 50.1 & 48.6 & 50.1 & 47.2 \\
\hline $\begin{array}{l}\text { Blaine Fineness } \\
\qquad\left(\mathrm{cm}^{2} / \mathrm{g}\right)\end{array}$ & 3704 & 4220 & 4229 & 4183 & 4108 & 4255 & 4156 & 4281 & 4180 & 4206 & 4185 \\
\hline Density $\left(\mathrm{g} / \mathrm{cm}^{3}\right)$ & 3.19 & 3.19 & 3.19 & 3.18 & 3.18 & 3.19 & 3.18 & 3.18 & 3.18 & 3.18 & 3.18 \\
\hline Water Demand \% & 23 & 25.9 & 25.8 & 25.1 & 25 & 25.9 & 25.8 & 24.8 & 25 & 25.5 & 25.5 \\
\hline $\mathrm{SiO}_{2} \%$ & 20.73 & 20.57 & 20.52 & 20.6 & 20.34 & 20.43 & 20.57 & 20.4 & 20.45 & 20.42 & 20.54 \\
\hline $\mathrm{Al}_{2} \mathrm{O}_{3} \%$ & 4.73 & 4.75 & 4.72 & 4.75 & 4.71 & 4.72 & 4.75 & 4.7 & 4.67 & 4.7 & 4.77 \\
\hline $\mathrm{Fe}_{2} \mathrm{O}_{3} \%$ & 3.89 & 3.92 & 3.9 & 3.91 & 3.92 & 3.91 & 3.91 & 3.89 & 3.89 & 3.9 & 3.92 \\
\hline $\mathrm{CaO} \%$ & 63.55 & 63.55 & 63.63 & 63.29 & 63.13 & 63.19 & 63.18 & 63.11 & 63.11 & 63.14 & 63.14 \\
\hline $\mathrm{MgO} \%$ & 1.12 & 1.13 & 1.11 & 1.12 & 1.12 & 1.14 & 1.12 & 1.11 & 1.13 & 1.13 & 1.11 \\
\hline $\mathrm{SO}_{3} \%$ & 3.14 & 3 & 3.04 & 3.05 & 3.06 & 3.09 & 3.08 & 3.1 & 3.1 & 3.09 & 3.04 \\
\hline $\mathrm{K}_{2} \mathrm{O} \%$ & 0.83 & 0.86 & 0.84 & 0.85 & 0.88 & 0.88 & 0.88 & 0.88 & 0.88 & 0.88 & 0.88 \\
\hline $\mathrm{Na}_{2} \mathrm{O} \%$ & 0.2 & 0.2 & 0.9 & 0.25 & 0.22 & 0.22 & 0.21 & 0.22 & 0.21 & 0.23 & 0.18 \\
\hline
\end{tabular}

$33 \%$ displacement resulted in reduced strength results of cement at all ages compared to those made with $100 \%$ MEG. The contribution of $25 \%$ of BA gave more decrease in all strength ages related than that of $33 \%$ BA mixture (Figure 1).

The differences between 2, 7 and 28 days strengths of $25 \%$ BA mixture experiment cement sample from 33\% BA mixture are less $0.7,1.3$ and $0.4 \mathrm{MPa}$ respectively (Figure 1). The relatively higher difference values in early strength ages ( 2 and 7 days) indicate another factor leading to early reactions. The Blaine of $33 \% \mathrm{BA}+\mathrm{MEG}$ experiment sample is a few higher $\left(+98 \mathrm{~cm}^{2} / \mathrm{gr}\right)$ which can speed the early hydration reactions (Table 2). Also according to the chemical analysis of both cement, it is seen a few $\mathrm{SO}_{3}$ difference that the amount of $\mathrm{SO}_{3}$ of $25 \% \mathrm{BA}+\mathrm{MEG}$ experiment sample is $3.05 \%$, and that of $33 \% \mathrm{BA}+\mathrm{MEG}$ experiment is 3.10. The $\mathrm{SO}_{3}$ increase also may cause the increase of early ages strengths although the \%BA content was increased in grinding aid mixture.

The 2 days compressive strength of the test made with $100 \%$ DEG as grinding aid is $2.5 \mathrm{MPa}$ higher than the compressive strength of the reference cement. The 7 days compressive strength of the same test is $0.5 \mathrm{MPa}$ higher than the 


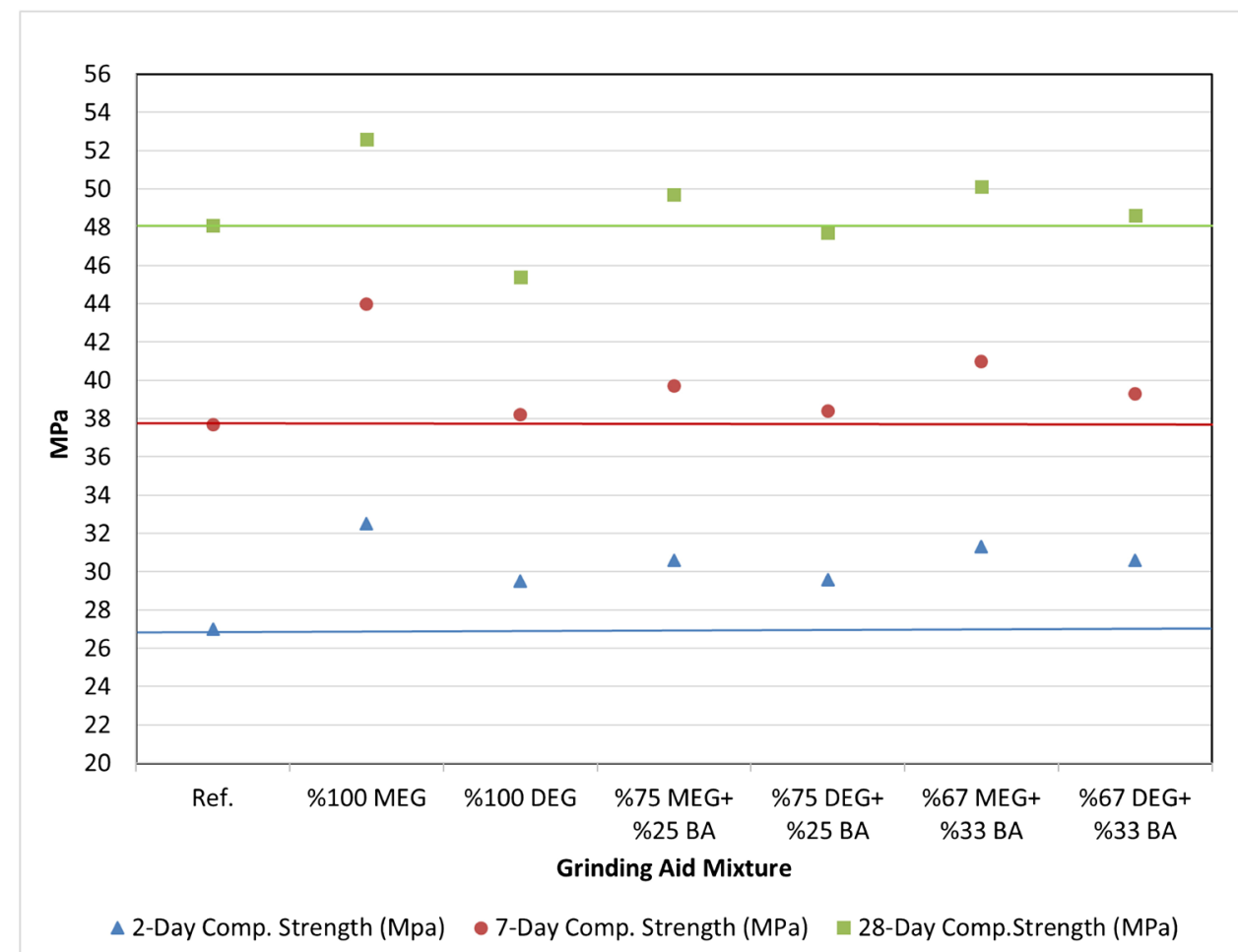

Figure 1. Comparisons of 2, 7 and 28 days compressive strength results of the experiments using boric acid added with $25 \%$ and $33 \%$ to glycol-based grinding aids and $100 \%$ grinding aids according to reference cement and comparison with each other.

compressive strength of the reference cement. Test result with 100\% DEG is 2.7 $\mathrm{MPa}$ less than the 28 days compressive strength of the reference cement. Addition of $100 \%$ DEG had an adverse effect on the 28 days compressive strength although it contributed to early ages strengths ( 2 and 7 days).

The compressive strength in 2 and 7-day tests using 25\% BA+ 75\% DEG is very similar to the compressive strength of experiments using $100 \%$ DEG and higher than the 2 and 7-day compressive strength results of the reference cement. The experiment using $25 \% \mathrm{BA}+75 \% \mathrm{DEG}$ is higher than the result of 28 days $100 \%$ DEG (2.3 MPa), but it is lower than $(0.4 \mathrm{MPa})$ the 28 day compressive of reference cement.

It was observed that boric had a positive effect to diethylene glycol performance especially on the 28 days compressive strength results by contributing as a grinding aid to the mixture. When the amount of boric acid was increased to $33 \%$, it was observed that the grinding aid DEG performances in all compressive strength ages increased and gave much higher results compared to the reference cement. As a theory the reason for this strength development could be the interaction between boric compounds and glycols:

In literature it is shown that boric acid acts more like a Lewis acid when dissolved in water (Equation (1)) [19].

$$
\mathrm{B}(\mathrm{OH})_{3}+2 \mathrm{H}_{2} \mathrm{O} \Leftrightarrow \mathrm{B}(\mathrm{OH})_{4}^{-}+\mathrm{H}_{3} \mathrm{O}^{+}
$$


The covalent product formed between boric acid and diol is called borate ester. These interactions proceed in the direction of occuring tetrahedral borate ester at basic $\mathrm{pH}$ levels (Figure 2) [19].

The displacement between the boric acids and the divalent ligands can be complex in the aqueous solution and may vary according to $\mathrm{pH}$ levels [20].

Boric acid may form either neutral or anionic esters depending on the $\mathrm{pH}$ level. Bond formation of boric acid to diols occurs at basic $\mathrm{pH}$ levels. Boric acid may form anionic tetrahedral diesters with diols or divalent ligands [20] (Figure 3). Borates form neutral esters in apolar solvents and form anionic borate ester in water. Borate esters almost do not form at physiological $\mathrm{pH}$ (7.5) levels; also they split in a strong acid medium [20]. PH level of fresh cement mortar is at least 12.5 [21].

Cement hydration reactions start with the addition of water to the cement mixture. After the water is added, the water moves on the particle voids. This cement-water mixture with a high $\mathrm{pH}$ level enables borate ester formation between the boron compounds and the diols (MEG and DEG) used in the experiments (Figure 3), and it is understood that these esters also influence the hydration reactions.

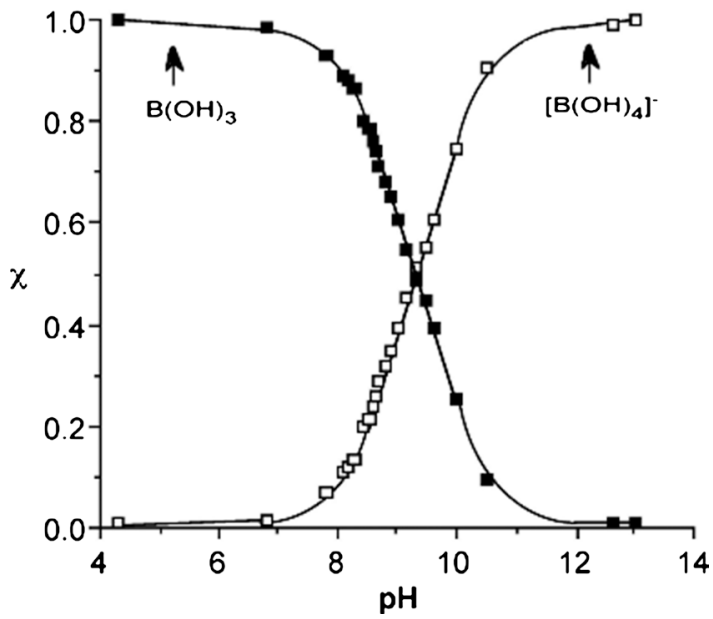

Figure 2. Change in mole ratios of boric acid (black boxes) and anions (white boxes) according to $\mathrm{pH}$ level, adapted from M. Bishop, N. Shahid, J. Yang ve A.R. Barron, Dalton Trans, 2004, 2621.

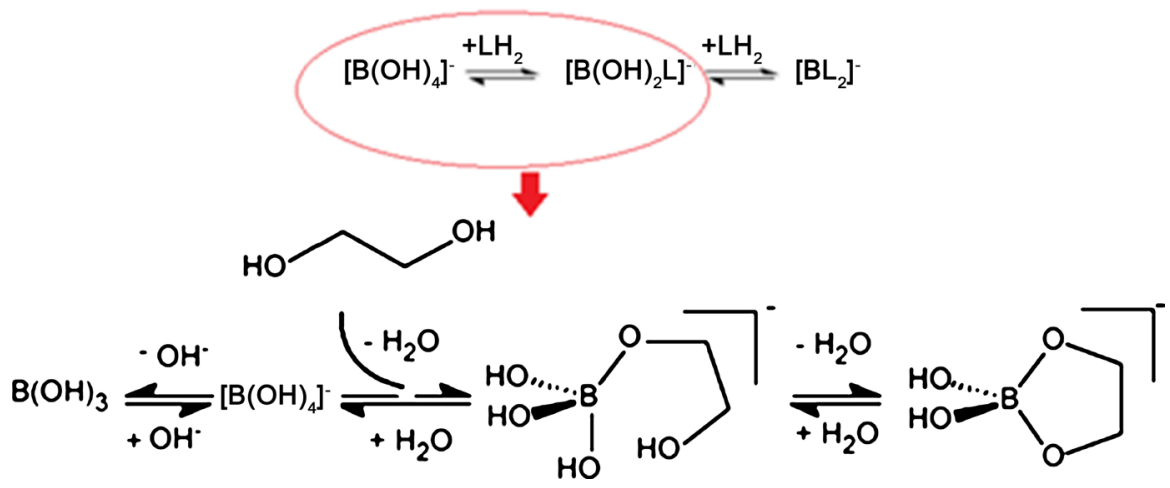

Figure 3. The possible esterification reaction of boric acid with glycols in alkaline medium. 
Borax is an important boron compound and boric acid salt. The powder borax is a white color and consists of soft, colorless crystals which are readily soluble in water. Borax dissolves in water to form boric acid. In alkaline environment boric acid yields tetrahydroxyborate anion.

The resulting increases in compressive strengths because of the interaction between the DEG and the boron compounds are similar to the results of Duan-le and others There is an increase in strength results of 2, 7 and 28 days after the formation of possible borate esters [16]. In other studies, DEG was used as a grinding aid with a dosage of $0.1 \%$, which resulted in a lower 28 days compressive strength compared to reference cement [13] [14]. These results were also seen in experiments using $100 \%$ DEG in this study. The use of boron compounds led to an increase in the performance of DEG as a grinding aid. The possible reason for this can be that the formed borate esters increase the degree of hydration, to trigger the formation of the hydration products and the optimization of the pore structure as shown in the Duan-le study, [16]. It means a significant increase in early ages ( 2 and 7 days) and 28 days compressive strength regarding mechanical properties.

The 2, 7 and 28 days compressive strength results of $\% 25$ AHB $+75 \%$ DEG mixture is higher $(0.8 ; 0.6$ and $3.4 \mathrm{MPa}$ respectively) than the results of the experiment with 100\% DEG (Figure 4). Likewise, the results of the tests with 25\% $\mathrm{AHB}+75 \%$ DEG are higher than those of the reference cement at 2, 7 and 28

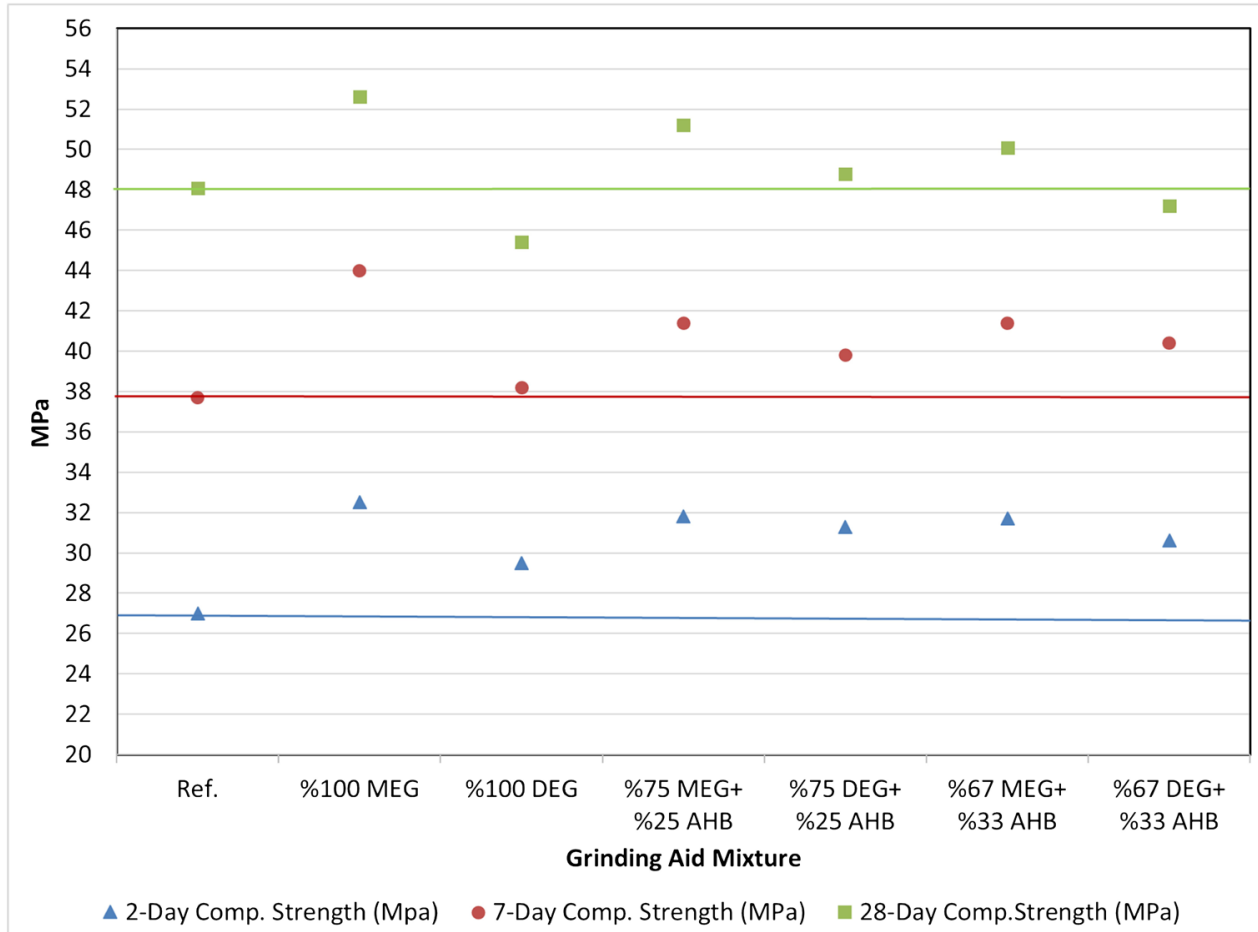

Figure 4. Comparisons of the results of 2,7 and 28 days compressive strength results of the experiments made with anhydrous borax and $25 \%$ and $33 \%$ additions to the glycol based grinding aids with respect to the reference cement and each other with $100 \%$ grinding aid. 
days compressive strengths. The compressive strength results for all ages of $33 \%$ $\mathrm{AHB}+67 \%$ DEG test are higher than those of the results done with 100\% DEG and except for the 7 days compressive strength results, 2 and 28 days compressive strength are lower than the results of $25 \%$ AHB $+75 \%$ DEG test (Figure 4). Although it gives higher results than the reference cement at 2 and 7 days strength ages, it gives lower result than the reference cement at 28 days. The $33 \%$ AHB mixture test showed a positive contribution to the DEG performance at the 28-day compressive strength, but it was not enough to be more than reference cement.

\section{Conclusion}

DEG was unable to yield the positive performance of MEG in the experiments according to the reference cement at 2, 7, 28 days compressive strength results. The use of boron compounds resulted in a significant increase in the compressive strength performance of the DEG as a grinding aid. The possible reason for this could most probably be the borate ester formation between boric acid and DEG in the alkaline medium formed during the cement hydration reactions. In the cement industry where energy use is intense, improvements in the performance of cement products will provide advantages in terms of cost reduction. Similarly, it is important that the performances of glycol-based grinding aids which have a price advantage compared to other chemicals (e.g., amine-based grinding aids) providing similar strength increases are of importance in the commercial issue. Industry-friendly results will be obtained when more studies in which the mixture ratios of DEG and boron compounds and the amount of addition of the mixture to the cement are to be found for higher strength increases.

\section{Availability of Data and Material}

The data set supporting the conclusions of this article included within the report that stored in

https://figshare.com/articles/ExperimentalDataM1M31_pdf/6809255.

\section{Acknowledgements}

This study supported by SYCS Construction and Cement Company.

\section{Funding}

Funds by Murat Çallı (Ph.D. Student in the Department of Chemical Engineering in Selcuk University and Quality Manager in SYCS Construction and Cement Company).

\section{Conflicts of Interests}

The authors and SYCS Construction and Cement Company declare that they have no conflicts of interests. 


\section{References}

[1] Ervanne, H. and Hakanen, M. (2007) Analysis of Cement Superplasticizers and Grinding Aids: A Literature Survey. University of Helsinki.

[2] Katsioti, M., Tsakiridis, P.E., Giannatos, P., Tsibouki, Z. and Marinos, J. (2009) Characterization of Various Cement Grinding Aids and Their Impact on Grindability and Cement Performance. Construction and Building Materials, 23, 1954-1959. https://doi.org/10.1016/j.conbuildmat.2008.09.003

[3] Sohoni, S., Sridhar, R. and Mandal, G. (1991) The Effect of Grinding Aids on the Fine Grinding of Limestone, Quartz and Portland Cement Clinker. Journal of Powder Technology, 67, 277-286. https://doi.org/10.1016/0032-5910(91)80109-V

[4] Jeknavorian, A.A., Barry, E.F. and Serafin, F. (1998) Determination of Grinding Aids in Portland Cement by Pyrolysis Gas Chromatography-Mass Spectrometry. Cement and Concrete Research, 28, 1335-1345. https://doi.org/10.1016/S0008-8846(98)00109-4

[5] Choi, H., Lee, W., Kim, D.U., Kumar, S., Kim, S.S., Chung, H.S., Kim, J.H. and Ahn, Y.C. (2010) Effect of Grinding Aids on the Grinding Energy Consumed during Grinding of Calcite in a Stirred Ball Mill. Minerals Engineering, 23, 54-57. https://doi.org/10.1016/j.mineng.2009.09.011

[6] Hasegawa, M., Kimata, M. and Yaguchi, M. (2005) Effect and Behavior of Liquid Additive Molecules in Dry Ultrafine Grinding of Limestone. Journal of the Society of Powder Technology, Japan, 42, 178-184.

[7] Elbeyli, İ.Y., Derun, E.M., Gülen, J. and Piskin, S. (2003) Thermal Analysis of Borogypsum and Its Effect on the Physical Properties of Portland Cement. Cement and Concrete Research, 33, 1729-1735. https://doi.org/10.1016/S0008-8846(03)00110-8

[8] Erdoğan, Y., Genç, H. and Demirbaş, A. (1992) Utilization of Borogypsum for Cement. Cement and Concrete Research, 22, 841-844. https://doi.org/10.1016/0008-8846(92)90108-8

[9] Ugurlu, A., Ozdemir, M. and Topcu, I. (2004) Bor içeren kil atıkların çimento içerisinde değerlendirilmesi. 2nd Uluslararası Bor Sempozyumu, Eskişehir-Türkiye, 405411.

[10] Koyuncu, H., Bakıs, R., Taspolat, L.T., Yılmaz, G. and Karacasu, M. (2004) An Investigation on Use of Borax Mineral as Portland Cement Replacement Material, 2. Uluslararası Bor Sempozyumu, Eskișehir-Türkiye, 463-475.

[11] Kula, I., Erdogan, Y., Olgun, A., Kalfa, O.M. and Sevinc, V. (2001) Effects of Colemanite Waste, Coal Bottom Ash and Fly Ash on the Properties of Cement. Cement and Concrete Research, 31, 491-494. https://doi.org/10.1016/S0008-8846(00)00486-5

[12] Bothe, J.V. and Brown, J.P.W. (1998) Phase Formation in the System $\mathrm{CaO}-\mathrm{Al}_{2} \mathrm{O}_{3}$ $\mathrm{B}_{2} \mathrm{O}_{3}-\mathrm{H}_{2} \mathrm{O}$ at $23 \pm 1^{\circ} \mathrm{C}$. Journal of Hazardous Materials, 63, 199-210. https://doi.org/10.1016/S0304-3894(98)00221-0

[13] Assaad, J.J. and Issa, C.A. (2015) Rheological Properties of Cement Pastes Containing Amine- and Glycol-Based Grinding Aids. Advances in Cement Research, 27, 28-41. https://doi.org/10.1680/adcr.13.00066

[14] Assaad, J.J., Asseily, S.E. and Harb, J. (2009) Use of Cement Grinding Aids to Optimize Clinker Factor. Advances in Cement Research, 21, 1-8.

[15] Schrabback, J.M. (2009) Polycarboxylate Polymer-Powered Grinding Efficiency. 
Global Cement Magazine.

[16] Li, D.-L., et al. (2018) Influence of Organic Esters on Portland Cement Hydration and Hardening. Advances in Materials Science and Engineering, 2018, Article ID 3203952.

[17] TS EN 197-1:2012, Çimento-Bölüm 1: Genel çimentolar-Bileşim. özellikler ve uygunluk kriterleri (Cement Part 1: Composition. Specification and Conformity Criteria for Common Cements).

[18] TS EN 196-1:2009 Çimento deney metotları-Bölüm 1: Dayanım tayini standardı (Methods of Testing Cement Part 1: Determination of Strength).

[19] Bishop, M., Shahid, N., Yang, J. and Barron, A.R. (2004) Determination of the Mode and Efficacy of the Cross-Linking of Guar by Borate Using MAS 11B NMR of Borate Cross-Linked Guar in Combination with Solution 11B NMR of Model Systems. Dalton Transactions, No. 17, 2621. https://doi.org/10.1039/B406952H

[20] Pappin, B., Kiefel, M.J. and Houston, T.A. (2012) Comprehensive Studies on Glycobiology and Glycotechnology. Carbohydrates, No. 3, 38-40.

[21] Taylor, H.F.W. (1997) Cement Chemistry. 2nd Edition, Thomas Telford Publishing, London, 5.7.2-142. https://doi.org/10.1680/cc.25929

\section{List of Abbreviations}

GA: Grinding aid

MEG: Monoethylene glycol

DEG: Diethylene glycol

BA: Boric acid

AHB: Anhydrous borax

TEA: Triethanolamine

TIPA: Triisopropanolamine

PG: Propylene glycol

PCE: Polycarboxylate ether

Eq.: Equation 